\title{
Cardioprotection and ageing
}

\author{
Yon Hee Shim
}

Department of Anesthesiology and Pain Medicine and Anaesthesia and Pain Research Institute, Yonsei University College of Medicine, Seoul, Korea

With an increase in the elderly population and an increase in the prevalence of age-related cardiovascular disease, anesthesiologists are increasingly being faced with elderly patients with known or suspected ischemic heart disease in the perioperative period. Although early reperfusion remains the best strategy to reduce ischemic injury, reperfusion may damage the myocardium. Adjuvant therapy to revascularization is therefore necessary. To develop better strategies to prevent ischemia-reperfusion injury in older patients, we need to understand the aged myocardium, which has undergone structural and functional changes relative to the normal myocardium, resulting in reduced functional capacity and vulnerability to ischemia-reperfusion injury. In addition, innate or acquired cardioprotection deteriorates with aging. These changes in the aged myocardium might explain why there is poor translation of basic research findings from young animals to older patients. In this review, I discuss changes in intracellular signaling associated with myocardial ageing that have an effect on ischemia-reperfusion injury, and I discuss the efficacy of cardioprotection afforded by ischemic and pharmacologic pre- and post-conditioning in the aged myocardium. Finally, I outline strategies to restore protection in the aged myocardium. (Korean J Anesthesiol 2010; 58: 223-230)

Key Words: Ageing, Cardioprotection, Diet, Exercise, Ischemia-reperfusion injury.

\section{Introduction}

The incidence and prevalence of cardiovascular diseases, including ischemic heart disease, are increasing in Korea, most likely due to the ageing of the population and adoption of a Westernized diet. Cardiovascular disease is the leading cause of mortality in the elderly. Two-thirds of myocardial infarctions occur in individuals older than 65 years-of-age, and $80 \%$ of deaths caused by myocardial infarction are in elderly patients.
These data indicate that ischemic heart disease is prevalent in the elderly, and that the mortality due to ischemic heart disease increases with ageing. According to the National Statistical Office, individuals aged 65 years or older comprised $9.9 \%$ of the Korean population in 2007, and this figure is expected to exceed $14 \%$ in 2013 , thus Korea is expected to become an 'aged society' in the near future. With the rapid increase in the elderly population, the incidence of ischemic heart disease in these elderly individuals is also expected to increase rapidly.

Received: March 4, 2010. Revised: 1st, March 5, 2010; 2nd, March 8, 2010. Accepted: March 8, 2010.

Corresponding author: Yon Hee Shim, M.D., Ph.D., Department of Anaesthesiology and Pain Medicine, Anaesthesia and Pain Research Institute, Yonsei University College of Medicine, 250, Seongsan-no, Seodaemun-gu, Seoul 120-752, Korea. Tel: 82-2-2227-4963, Fax: 82-2-3127185, E-mail: tren125@yuhs.ac

(C) This is an open-access article distributed under the terms of the Creative Commons Attribution Non-Commercial License (http:// creativecommons.org/licenses/by-nc/3.0/), which permits unrestricted non-commercial use, distribution, and reproduction in any medium, provided the original work is properly cited. 
Aggressive therapeutic strategies may be required to treat ischemic heart disease in the elderly in order to improve their qualities of life.

Although reperfusion remains the best strategy for the treatment of ischemic heart disease, reperfusion itself injures the myocardium. A study that targeted patients with acute myocardial infarction showed that mortality is higher and left ventricular dysfunction is greater in patients aged 75 years or older despite successful revascularization with thrombolysis [1]. This study proved that the aged myocardium is sensitive to reperfusion injury. Off-pump coronary artery bypass graft surgery has increased the prevalence of cardiac surgery performed in the elderly. Although off- pump coronary artery bypass graft surgery has several advantages such as less neurologic complications and less inflammatory reactions, ischemia-reperfusion injury is not avoidable because of the elevation of the heart during surgery and transient occlusion for coronary anastomosis. Thus, it is very important to develop strategies to reduce ischemia-reperfusion injuries in the aged myocardium during the perioperative period.

A multitude of studies have investigated strategies to protect the heart against ischemia-reperfusion injury, either by ischemic pre- and post-conditioning or by mimics of pharmacologic stimuli. However, the clinical data are inconsistent. The poor translation of basic research results to clinical application may be due to the characteristics of the target population; although most experimental studies have been performed in healthy young animals, the patients in the operating room are diseased and old. We therefore need to understand the aged myocardium in order to develop strategies to reduce myocardial ischemia-reperfusion injuries in these patients.

In this review, I discuss (1) functional and structural changes in the aged myocardium, especially mitochondrial changes, (2) the increased susceptibility to ischemia-reperfusion injury that is characteristic of the aged myocardium, including the changes in intracellular signaling important to ischemia-reperfusion injury, (3) loss of cardioprotection with ageing, and finally (4) strategies to restore protection in the aged myocardium.

\section{Functional and structural changes in the aged myocardium}

Ageing affects cardiomyocytes at different levels. At the level of DNA, mutations and telomere shortening are observed in the aged myocardium. Telomere shortening might be associated with limited regenerative capacity [2] and increased mortality [3]. Based on changes in nuclear and mitochondrial gene expression profiles, protein expression in the aged myocardium is altered and is associated with a shift from fatty acid to carbohydrate metabolism and changes in intracellular matrix and signal transduction components [4]. The handling of cellular waste by autophagy is also altered. Aged cardiomyocytes have decreased tolerance to stress such as ischemia-reperfusion and increased susceptibility to apoptosis and necrosis. Increased apoptosis and necrosis reduce the number of cardiomyocytes and result in the development of hypertrophy in the remaining cardiomyocytes. All of these changes decrease contractile function, resulting in decreased left ventricular systolic and diastolic function and decreased peak cardiac output [5].

Mitochondria are the powerhouses of the cell. Energy supplied by mitochondrial oxidative phosphorylation provides more than $70 \%$ of the ATP that the myocardium requires [6]. Mitochondria also control ion homeostasis, generate reactive oxygen species (ROS), and are involved in apoptotic/antiapoptotic signaling. Aged cardiomyocytes are sensitive to oxidative stress, which injures mitochondria and makes them larger. These giant mitochondria are not removed by autophagy, and they accumulate in the cardiomyocytes. These injured mitochondria contain damaged, mutated DNA, resulting in the production of mutant proteins, which accelerate ROS generation in aged cardiomyocytes. In addition to excessive generation of ROS, the antioxidant capacity of cells decreases with aging due to increases in levels of manganese-containing superoxide dismutase and decreases in either catalase or glutathione. Mitochondria also play an important role in endogenous cardioprotection. The opening of the mitochondria permeability transition pore (MPTP) is critical for the initiation of cell death [7]. In aged mitochondria, MPTP opening has been observed to be more sensitive than that in young mitochondria [8].

The expression and/or activity of protein kinases, which play a critical role in cardioprotection, are also altered in the aged myocardium (Table 1). The expression level or phosphorylation status of reperfusion injury salvage kinase (RISK) elements, including Akt (protein kinase B), ERK1/2 (extracellular signalregulated kinase $1 / 2$ ), and GSK $3 \beta$ (glycogen synthase kinase $3 \beta$ ), are altered in the aged myocardium. Phosphatases such as protein phosphatase 2A (PP2A) or protein tyrosine phosphatase 1B (PTP1B, which reduce phosphorylation of proteins and suppress their activation, are increased. Levels of Cx43 (connexin 43), STAT3 (signal transducer and activator of transcription 3), and Sirt 1 (sirtuin), which play a role in cardioprotection, are also decreased.

Aged cardiomyocytes are susceptible to calcium overloading $[8,9]$ because of a reduction in the density and activity of calcium regulating proteins such as the $\mathrm{Na}^{+} / \mathrm{Ca}^{2+}$ exchanger, $\mathrm{Ca}^{2+}$ ATPase, and ryanodine receptor [10-13]. In addition, modification of the amount and composition of cardiolipin in mitochondria [14] contributes to the breakdown of calcium 
Table 1. Age-associated Alterations in the Expression/Activity of Proteins Involved in Cardioprotection

\begin{tabular}{llll}
\hline \multicolumn{1}{c}{ Protein } & \multicolumn{1}{c}{$\begin{array}{c}\text { Species/Age } \\
\text { (months) }\end{array}$} & \multicolumn{1}{c}{ Expression/Activity } & Reference \\
\hline MnSOD & $\begin{array}{l}\text { Rat } / 24 \text { mo } \\
\text { Rat } / 31-34 \text { mo }\end{array}$ & $\begin{array}{l}\text { Decreased } \\
\text { No change in protein level } \\
\text { Decreased SOD activity }\end{array}$ & {$[16]$} \\
& & Decreased & {$[17]$} \\
Catalase & Rat $/ 24$ mo & No change & {$[16]$} \\
PKC $\varepsilon$ & Mouse $/>13$ mo & Decreased & {$[19]$} \\
& Rat $/ 24$ mo & Decreased & {$[20]$} \\
ERK1/2 & Rat $/ 18$ mo & Increased phosphorylation & {$[21]$} \\
Akt & Rat $/ 23$ mo & {$[22]$} \\
& Mouse $/ 26-28$ mo & Decreased total form & {$[21]$} \\
GSK $3 \beta$ & Rat $/ 23$ mo & Decreased & {$[23]$} \\
MKP-1 & Mouse $/ 20-24$ mo & Increased & {$[22]$} \\
PTP1B & Mouse $/ 26-28$ mo & Increased & {$[23]$} \\
PP2A & Rat $/ 21-22$ mo & Increased & {$[18]$} \\
Cx43 & Mouse $/>13$ mo & Decreased & {$[18]$} \\
STAT3 & Mouse $/>13$ mo & Decreased & {$[16]$} \\
Sirt 1 & Rat $/ 24$ mo & Decreased & {$[24]$} \\
iNOS & Mouse $/ 16$ mo & Increased & {$[25]$} \\
& Mouse $28-31$ mo & Increased &
\end{tabular}

MnSOD: manganese superoxide dismutase, $\mathrm{PKC} \varepsilon$ : protein kinase $\mathrm{C} \varepsilon$, ERK1/2: extracellular signal-regulated kinase 1/2, Akt: protein kinase B, GSK3 $\beta$ : glycogen synthase kinase $3 \beta$, MKP-1: mitogen-activated kinase phosphatase 1, PTP1B: protein tyrosine phosphatase 1B, PP2A: protein phosphatase 2A, Cx43: connexin 43, STAT3: signal transducer and activator of transcription 3, Sirtl: sirtuin, iNOS: inducible nitric oxide synthase, mo: month. Table is modified from ref [26].

homeostasis, which is susceptible to the opening of MPTP [15].

\section{Ischemia-reperfusion injury in the aged myocardium}

Advanced age is an independent risk factor for poor cardiac outcome. With ageing, comorbidities such as hypertension, atherosclerosis, congestive heart failure, or diabetes may affect the sensitivity of the aged myocardium to ischemia-reperfusion injury. However, several studies have shown that increased mortality in the elderly is independent of the presence of hypertension, diabetes, previous myocardial infarction, number of diseased coronary arteries, and the location of infarction $[15,27]$. These results indicate that the aged myocardium is vulnerable to ischemia-reperfusion injury.

The aged myocardium has decreased tolerance to ischemiareperfusion injury, though the ischemic threshold is not affected by age (Fig. 1). Decreased tolerance to ischemiareperfusion injury has been demonstrated in middle-aged mice (12 months); this decreased tolerance became more prominent with ageing (18 months and 24-28 months) [29]. However, the results from a study of the human atrium were inconsistent. Although creatine kinase release after $90 \mathrm{~min}$ of ischemia followed by 120 min of reperfusion was not affected by age [30], the recovery of contractile force after $30 \mathrm{~min}$ of hypoxia

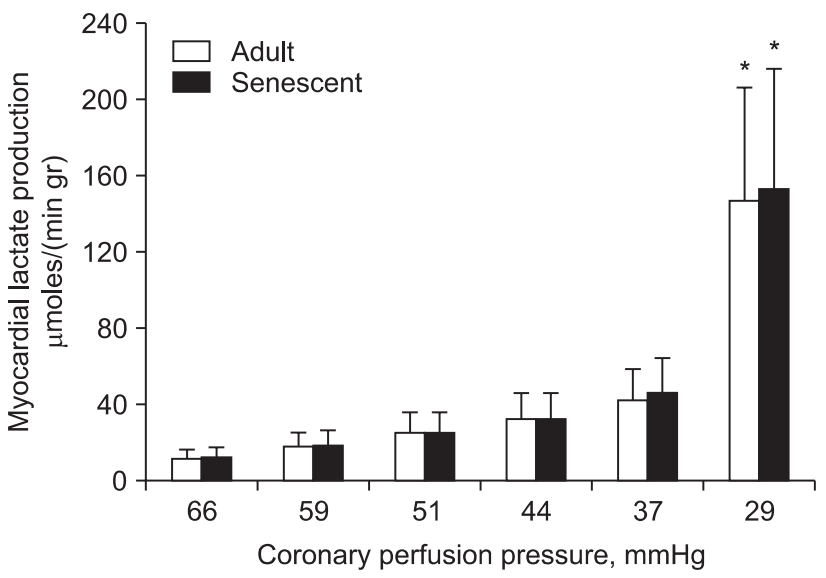

Fig. 1. Effect of reducing coronary perfusion pressure on myocardial lactate production in adult and old hearts. This figure is taken from [28].

followed by $30 \mathrm{~min}$ of reoxygenation was reduced in the atrium of patients aged 60 years or older compared to that of adults younger than 60 years [31].

The increased susceptibility to ischemia-reperfusion injury seen in the aged myocardium might be associated with enhanced oxidative stress. Oxidative damage was found to be aggravated in the aged myocardium of 20-month-old rats [30] and reperfusion with superoxide dismutase and catalase improved contractile function. Furthermore, treatment of the aged myocardium of 24-month-old rats with acetylcarnitine improved the recovery of contractile function and reduced lactated dehydrogenase levels [32].

\section{Loss of protection in the aged myocardium}

\section{Ischemic preconditioning (IPC)}

Since the first demonstration of ischemic preconditioning in 1986 by Murray et al., IPC has been considered to be one of the strongest forms of endogenous cardioprotection. IPC has two different phases; an early phase that develops within a few minutes and lasts up 2-4 hours and a late phase that develops 6-12 hours and lasts up to 4 days. Complex intracellular signaling pathways mediate IPC, and ROS generated in the mitochondria act as triggers or mediators. Although several effector candidates have been evaluated, the evidence that MPTPs or mitochondrial $\mathrm{K}_{\text {ATP }}$ channels are the effectors is most convincing (Fig. 2). Although simplification of the cascades into a trigger, mediator, and effector can help to clarify the mechanism of IPC, it should be kept in mind that there is crosstalk between the underlying signaling components and that the underlying mechanism is more complex.

The effect of ageing on the ability of preconditioning to protect 


\begin{tabular}{lll}
\multicolumn{1}{c}{ Trigger } & Mediator & End effector \\
- Receptor dependent & PKC & SarcK $_{\text {ATP }}$ channel \\
Adenosin & P38MAPK & mitoK $_{\text {ATP }}$ channel \\
Opioid receptors & PKA & Alterations in fatty acid metabolism (?) \\
- Receptor independent & PKB (Akt) & \\
ROS & PKG & MPTP (mitochondrial permeability \\
NO (?) & ERK & transition pore) \\
$\mathrm{Ca}^{2+}$ & PI3K & \\
& GSK 3-beta &
\end{tabular}

Fig. 2. Cascades of ischemic preconditioning.

Table 2. Effects of Age on Cardioprotection by Ischemic Preconditioning

\begin{tabular}{|c|c|c|c|c|c|}
\hline Species & Model & Age & Endpoint & Cardioprotection in the aged heart & Reference \\
\hline Rat & Isolated heart & $12 \mathrm{wk} / 50 \mathrm{wk}$ & Hemodynamic, CK & No & [33] \\
\hline Rat & Isolated heart & $2 \mathrm{mo} / 6 \mathrm{mo} / 20 \mathrm{mo}$ & Hemodynamics & No & [34] \\
\hline Rat & Isolated heart & $6 \mathrm{mo} / 20 \mathrm{mo}$ & Hemodynamics & $\begin{array}{l}\text { No in sedentary } \\
\text { Yes in trained }\end{array}$ & [35] \\
\hline Rat & Isolated heart & $6 \mathrm{mo} / 24 \mathrm{mo}$ & Hemodynamics & $\begin{array}{l}\text { No in AD Lib, } \\
\text { Yes in CR }\end{array}$ & {$[36]$} \\
\hline Rat & Isolated heart & $3 \mathrm{mo} / 12 \mathrm{mo} / 18-20 \mathrm{mo}$ & Infarct size & No & [37] \\
\hline Mouse & In vivo & $<3 \mathrm{mo} />13 \mathrm{mo}$ & Infarct size & No & [18] \\
\hline Rabbit & In vivo & $2 \mathrm{yr} / 4 \mathrm{yr}$ & Necrosis & Yes & [38] \\
\hline Sheep & In vivo & $0.5-1 \mathrm{yr} / 5.7-8 \mathrm{yr}$ & Infarct size & Yes & [39] \\
\hline
\end{tabular}

mo: month, wk: week, yr: year, AD Lib: Ad libitum, CR: caloric restriction.

Table 3. Maximal Life Span [40]

\begin{tabular}{lc}
\hline Species & Maximal life span \\
\hline Mouse & $42 \mathrm{mo}$ \\
Rat & $48 \mathrm{mo}$ \\
Rabbit & $13 \mathrm{yr}$ \\
Sheep & $20 \mathrm{yr}$ \\
Dog & $22 \mathrm{yr}$ \\
Pig & $27 \mathrm{yr}$ \\
Human & $122 \mathrm{yr}$ \\
\hline
\end{tabular}

hearts from ischemia-reperfusion injury has been studied intensively (Table 2). The majority of studies demonstrated loss of cardioprotection by IPC with ageing. However, IPC was preserved in 2- 4-year-old rabbits [38] and 5.7- to 8-year-old sheep [39]. Based on the maximal life span of these species (Table 3), however, it is unlikely that these animals are suitable models for investigating ageing in humans.

When preconditioning stimuli were increased, cardioprotection was achieved in middle-aged rats. However, cardioprotection induced by IPC was lost in the aged rats, irrespective of the strength of the stimuli (Fig. 3). Indirect data using agonists for receptors or channel openers involved in cardioprotection showed that IPC signaling cascades are impaired in the aged myocardium [37].

IPC has been shown to occur naturally in the form of pro-

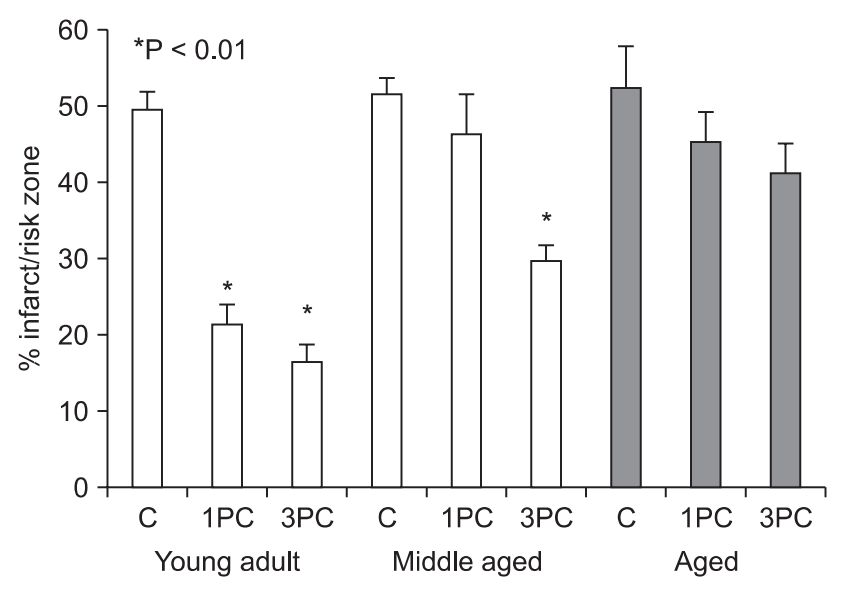

Fig. 3. Effect of one 5-min preconditioning cycle (1PC) and three 5 -min preconditioning cycles (3PC) on infarct size in young-adult, middle-aged, and aged rat hearts. C: control. This figure was taken from [37].

dromal angina prior to acute myocardial infarction, reducing the infarct size in patients $[41,42]$. In clinical studies, the measurement of infarct size is not available as an end-point, and surrogate end-points are used. For examples, ST changes on EKG, biologic markers such as creatine kinase (CK), CK$\mathrm{MB}$, and troponin-T, and clinical outcomes such as recovery of cardiac functions, length of hospital stay, mortality, and 
morbidity are frequently used. Clinical studies of IPC during revascularization and prodromal angina within a $48 \mathrm{~h}$ prior infarction have consistently demonstrated that IPC is not cardioprotective in elderly patients in terms of recovery of cardiac function, biologic markers, or clinical outcomes [43-45]. However, in vitro studies have showed less consistent results. After IPC in elderly patients, biological markers such as CK were reduced, but contractile function did not improve. Apart from age, comorbidities and medications such as angiotensinconverting enzymes $[46,47]$, COX-2 inhibitors, or sulfonylureas [48] complicate analysis of the IPC effect in the elderly.

\section{Pharmacologic preconditioning}

Anesthetic preconditioning (APC) by isoflurane was found to be effective in middle-aged (10-12 months), but not in aged rat hearts (20-24 months) [49,50]. Similarly, in isolated guinea-pig hearts, APC by sevoflurane was attenuated with ageing. Helium preconditioning-induced cardioprotection was not preserved in aged rat hearts [51], and enkephalin preconditioning did not protect aged mouse hearts (24-26 months) [52]. Interestingly, chronic morphine treatment was shown to be cardioprotective via protein kinase $\mathrm{A}$ in the aged heart in contrast to loss of acute morphine treatment in the aged heart [53].

Several components of the aged myocardium, included cardioprotection by APC, may be defective. The increase in ROS due to APC is impaired in the aged myocardium, even though the baseline ROS level is high in the aged myocardium [49]. Coupling between the opioid receptor and p38 MAPK (mitogen-activated protein kinase) was shown to be lost in the aged mouse heart, and phosphorylation of the downstream protein HSP27 (Heat shock protein 27) was reduced [52,53].

\section{Ischemic and pharmacologic postconditioning}

Interventions performed at reperfusion to protect the myocardium, such as post-conditioning, may be more clinically relevant because it is difficult to anticipate when an ischemic event will occur. IPC is not cardioprotective in aged mice [23]. However, the cardioprotective effect of IPC depends on the stimuli strength in the middle-aged myocardium [54]. The loss of the IPC effect in the aged myocardium was associated with reduced expression and phosphorylation of STAT3 $[54,55]$. Furthermore, levels of the phosphatase MKP1 were increased in the aged myocardium, and inhibition of MKP-1 resulted in the restoration of cardioprotection by ischemic postconditioning [23]. ERK, a target protein of MKP1 , was not activated by ischemic postconditioning in the aged myocardium, but was restored in aged hearts treated by a MKP1 inhibitor [38]. Therefore, in the aged heart, impaired activation of ERK 1/2 might affect downstream components such as STAT3. I found that isoflurane-induced postconditioning was not cardioprotective in old rats (20-24 months) (data not published). The reperfusion salvage kinase pathway, including Akt, its downstream effector GSK3 $\beta$, and ERK1/2 was not activated by anesthetic postconditioning, which may be associated with the loss of cardioprotection in the aged rat heart. Therefore, the aged myocardium is not protected by preor post-conditioning, which is associated with impaired signal transduction pathways.

\section{Restoration of protection in the aged my- ocardium}

\section{Diet}

Caloric restriction attenuates cellular ageing and promotes longevity $[4,56]$. Furthermore, caloric restriction renders cardiomyocytes resistant to ischemic injury. In food-restricted old rats, the cardioprotective effect of ischemic precondition was preserved [36]. Recovery of the developed pressure after ischemia-reperfusion and the occurrence of arrhythmia were evaluated in 6- and 24-month-old rats that had been on a caloric restriction diet since weaning [36,57]. The recovery of developed pressure was partially improved and arrhythmia was reduced in the food-restricted old rats. In a study of short-term caloric restriction, 24 -month-old rats were fed $90 \%$ of their caloric intake ad libitum for 2 weeks followed by $65 \%$ of their caloric intake ad libitum for 2 weeks. The left ventricular pressure was then evaluated in isolated perfused hearts. These authors found that short-term caloric restriction improved tolerance to ischemia, but did not restore IPC-induced cardioprotection [57]. Increased tolerance to ischemia by short-term caloric restriction was related to increased phosphorylation of AMPactivated kinase [58]. Increased levels of adiponectin induced by caloric restriction may contribute to the restoration of the IPC effect in aged hearts $[58,59]$.

\section{Exercise}

Exercise contributes to the preservation of endogenous cardioprotection in the aged heart. Elderly rats (24-month-old) were trained using a swimming protocol of $40 \mathrm{~min} /$ day, 5 days/ week for 6 weeks. Developed pressure in the left ventricle was partially improved by IPC in these trained rats. However, the combination of caloric restriction and exercise restored IPCbased cardioprotection more completely [60]. The mechanisms of exercise-induced cardioprotection or restoration of endogenous cardioprotection are not clear. However, a reduction in mitochondrial ROS formation, increased coronary 
circulation, increased levels of antioxidants such as manganese superoxide dismutase and catalase, altered expression of mitochondrial and sarcoplasmic $\mathrm{K}_{\mathrm{ATP}}$ channels, and altered gene/protein expression/activation of factors such as HSP and IGF-1 may contribute to exercise-induced cardioprotection [62].

The beneficial effects of exercise on IPC-induced cardioprotection have been demonstrated in elderly patients. High levels of physical activity preserve the cardioprotective effect of prodromal angina in elderly patients [62].

\section{Conclusions}

The prevalence of elderly patients with ischemic heart disease is expected to increase as life expectancy and the prevalence of ischemic heart disease increase. We therefore need to understand the characteristics of the aged myocardium and develop strategies to limit ischemia-reperfusion injury in the aged myocardium. Even though the mechanisms of increased susceptibility to ischemia-reperfusion and loss of protection in the aged heart are not fully elucidated, the aged myocardium is known to undergo structural and functional changes associated with impaired signal transduction. These changes may be associated with increased vulnerability to ischemia-reperfusion injury and loss of cardioprotection characteristic of the aged myocardium.

Most experimental studies have evaluated APC in healthy juvenile hearts. Unfortunately, this is far from the clinical reality. Most cardiac events in humans occur later in life, and most patients have comorbidities such as diabetes or hypercholesterolemia. Importantly, aged and diseased hearts behave differently from younger and healthier hearts. Future studies should focus on targeting populations with an aged or diseased myocardium. Furthermore, a more detailed understanding of the molecular mechanisms altered in the aged myocardium is required to identify candidates for pharmacologic manipulation. If cardioprotection is not triggered by ageing or certain drugs, cardioprotection can be provoked by activation of cell surface receptors. However, if activation of receptors or intracellular transduction signaling pathways is impaired, pharmacological agents acting proximal to or at the end-effector might bypass the age-related defects and provide cardioprotection. For example, inhibitors of MPTP might be cardioprotective in the aged myocardium by preventing the opening of the MPTP. However, it is not yet known whether functioning of the MPTP is altered in the aged myocardium, and the function of the MPTP has not been thoroughly elucidated.

Although exercise and caloric restriction might potentially restore endogenous cardioprotection, these are primary prevention strategies rather than strategies adjuvant to revascularization. Stem cell therapy may replace the damaged myocardium or restore endogenous cardioprotection in the aged myocardium $[38,63]$. However, the differentiation, replication, and long-term stability of stem cells need to be studied further. Research on the mechanisms of endogenous cardioprotection and their alteration with ageing is required to develop effective strategies to reduce ischemia-reperfusion injury in the elderly.

\section{References}

1. Lesnefsky EJ, Lundergan CF, Hodgson JM, Nair R, Reiner JS, Greenhouse SW, et al. Increased left ventricular dysfunction in elderly patients despite successful thrombolysis: the GUSTO-I angiographic experience. J Am Coll Cardiol 1996; 28: 331-7.

2. Nadal-Ginard B, Kajstura J, Leri A, Anversa P. Myocyte death, growth, and regeneration in cardiac hypertrophy and failure. Circ Res 2003; 92: 139-50.

3. Cawthon RM, Smith KR, O'Brien E, Sivatchenko A, Kerber RA. Association between telomere length in blood and mortality in people aged 60 years or older. Lancet 2003; 361: 393-5.

4. Lee CK, Allison DB, Brand J, Weindruch R, Prolla TA. Transcriptional profiles associated with aging and middle age-onset caloric restriction in mouse hearts. Proc Natl Acad Sci U S A 2002; 99: 14988-93.

5. Goldspink DF, Burniston JG, Tan LB. Cardiomyocyte death and the ageing and failing heart. Exp Physiol 2003; 88: 447-58.

6. Menon V, Webb JG, Hillis LD, Sleeper LA, Abboud R, Dzavik V, et al. Outcome and profile of ventricular septal rupture with cardiogenic shock after myocardial infarction: a report from the SHOCK Trial Registry. SHould we emergently revascularize Occluded Coronaries in cardiogenic shocK? J Am Coll Cardiol 2000; 36: 1110-6.

7. Downey JM, Cohen MV. Unraveling the mysteries of classical preconditioning. J Mol Cell Cardiol 2005; 39: 845-8.

8. Ataka K, Chen D, Levitsky S, Jimenez E, Feinberg H. Effect of aging on intracellular $\mathrm{Ca} 2+, \mathrm{pHi}$, and contractility during ischemia and reperfusion. Circulation 1992; 86: II371-6.

9. Frolkis VV, Frolkis RA, Mkhitarian LS, Shevchuk VG, Fraifeld VE, Vakulenko LG, et al. Contractile function and Ca2+ transport system of myocardium in ageing. Gerontology 1988; 34: 64-74.

10. Ashton KJ, Willems L, Holmgren K, Ferreira L, Headrick JP. Ageassociated shifts in cardiac gene transcription and transcriptional responses to ischemic stress. Exp Gerontol 2006; 41: 189-204.

11. Besse S, Delcayre C, Chevalier B, Hardouin S, Heymes C, Bourgeois $\mathrm{F}$, et al. Is the senescent heart overloaded and already failing? Cardiovasc Drugs Ther 1994; 8: 581-7.

12. Jahangir A, Sagar S, Terzic A. Aging and cardioprotection. J Appl Physiol 2007; 103: 2120-8.

13. Kaplan P, Jurkovicova D, Babusikova E, Hudecova S, Racay P, Sirova $\mathrm{M}$, et al. Effect of aging on the expression of intracellular $\mathrm{Ca}(2+)$ transport proteins in a rat heart. Mol Cell Biochem 2007; 301: 21926.

14. Pepe S. Mitochondrial function in ischaemia and reperfusion of the ageing heart. Clin Exp Pharmacol Physiol 2000; 27: 745-50.

15. Hausenloy DJ, Yellon DM. Survival kinases in ischemic precon- 
ditioning and postconditioning. Cardiovasc Res 2006; 70: 240-53.

16. Ferrara N, Rinaldi B, Corbi G, Conti V, Stiuso P, Boccuti S, et al. Exercise training promotes SIRT1 activity in aged rats. Rejuvenation Res 2008; 11: 139-50.

17. van der Loo B, Bachschmid M, Labugger R, Schildknecht $S$, Kilo J, Hahn R, et al. Expression and activity patterns of nitric oxide synthases and antioxidant enzymes reveal a substantial heterogeneity between cardiac and vascular aging in the rat. Biogerontology 2005; 6: 325-34.

18. Boengler K, Konietzka I, Buechert A, Heinen Y, Garcia-Dorado D, Heusch G, et al. Loss of ischemic preconditioning's cardioprotection in aged mouse hearts is associated with reduced gap junctional and mitochondrial levels of connexin 43. Am J Physiol Heart Circ Physiol 2007; 292: H1764-9.

19. Korzick DH, Holiman DA, Boluyt MO, Laughlin MH, Lakatta EG. Diminished alpha1-adrenergic-mediated contraction and translocation of PKC in senescent rat heart. Am J Physiol Heart Circ Physiol 2001; 281: H581-9.

20. Aoyagi T, Izumo S. Hemodynamic overload-induced activation of myocardial mitogen-activated protein kinases in vivo : augmented responses in young spontaneously hypertensive rats and diminished responses in aged fischer 344 rats. Hypertension 2001; 37: 52-7.

21. Hunter JC, Kostyak JC, Novotny JL, Simpson AM, Korzick DH. Estrogen deficiency decreases ischemic tolerance in the aged rat heart: roles of PKCdelta, PKCepsilon, Akt, and GSK3beta. Am J Physiol Regul Integr Comp Physiol 2007; 292: R800-9.

22. Fang CX, Doser TA, Yang X, Sreejayan N, Ren J. Metallothionein antagonizes aging-induced cardiac contractile dysfunction: role of PTP1B, insulin receptor tyrosine phosphorylation and Akt. Aging Cell 2006; 5: 177-85.

23. Przyklenk K, Maynard M, Darling CE, Whittaker P. Aging mouse hearts are refractory to infarct size reduction with postconditioning. J Am Coll Cardiol 2008; 51: 1393-8.

24. Yang B, Larson DF, Watson RR. Modulation of iNOS activity in agerelated cardiac dysfunction. Life Sci 2004; 75: 655-67.

25. Batkai S, Rajesh M, Mukhopadhyay P, Hasko G, Liaudet L, Cravatt $\mathrm{BF}$, et al. Decreased age-related cardiac dysfunction, myocardial nitrative stress, inflammatory gene expression, and apoptosis in mice lacking fatty acid amide hydrolase. Am J Physiol Heart Circ Physiol 2007; 293: H909-18.

26. Boengler K, Schulz R, Heusch G. Loss of cardioprotection with ageing. Cardiovasc Res 2009; 83: 247-61.

27. Mehta RH, Rathore SS, Radford MJ, Wang Y, Krumholz HM. Acute myocardial infarction in the elderly: differences by age. J Am Coll Cardiol 2001; 38: 736-41.

28. Abete P, Cioppa A, Calabrese C, Pascucci I, Cacciatore F, Napoli $\mathrm{C}$, et al. Ischemic threshold and myocardial stunning in the aging heart. Exp Gerontol 1999; 34: 875-84.

29. Willems L, Zatta A, Holmgren K, Ashton KJ, Headrick JP. Agerelated changes in ischemic tolerance in male and female mouse hearts. J Mol Cell Cardiol 2005; 38: 245-56.

30. Finkel T, Holbrook NJ. Oxidants, oxidative stress and the biology of ageing. Nature 2000; 408: 239-47.

31. Gerstenblith G, Frederiksen J, Yin FC, Fortuin NJ, Lakatta EG, Weisfeldt ML. Echocardiographic assessment of a normal adult aging population. Circulation 1977; 56: 273-8.

32. Lesnefsky EJ, He D, Moghaddas S, Hoppel CL. Reversal of mitochondrial defects before ischemia protects the aged heart. FASEB J 2006; 20: 1543-5.

33. Tani M, Suganuma Y, Hasegawa H, Shinmura K, Ebihara Y, Hayashi $\mathrm{Y}$, et al. Decrease in ischemic tolerance with aging in isolated perfused Fischer 344 rat hearts: relation to increases in intracellular $\mathrm{Na}+$ after ischemia. J Mol Cell Cardiol 1997; 29: 3081-9.

34. Lu LF, Fiscus RR. Calcitonin gene-related peptide causes long-term inhibition of contraction in rat thoracic aorta through a nitric oxidedependent pathway. Neuropeptides 1999; 33: 145-54.

35. Abete P, Calabrese C, Ferrara N, Cioppa A, Pisanelli P, Cacciatore $\mathrm{F}$, et al. Exercise training restores ischemic preconditioning in the aging heart. J Am Coll Cardiol 2000; 36: 643-50.

36. Abete P, Testa G, Ferrara N, De Santis D, Capaccio P, Viati L, et al. Cardioprotective effect of ischemic preconditioning is preserved in food-restricted senescent rats. Am J Physiol Heart Circ Physiol 2002; 282: H1978-87.

37. Schulman D, Latchman DS, Yellon DM. Effect of aging on the ability of preconditioning to protect rat hearts from ischemia-reperfusion injury. Am J Physiol Heart Circ Physiol 2001; 281: H1630-6.

38. Przyklenk K, Li G, Whittaker P. No loss in the in vivo efficacy of ischemic preconditioning in middle-aged and old rabbits. J Am Coll Cardiol 2001; 38: 1741-7.

39. Burns PG, Krunkenkamp IB, Calderone CA, Kirvaitis RJ, Gaudette GR, Levitsky S. Is the preconditioning response conserved in senescent myocardium? Ann Thorac Surg 1996; 61: 925-9.

40. Barja G, Herrero A. Oxidative damage to mitochondrial DNA is inversely related to maximum life span in the heart and brain of mammals. FASEB J 2000; 14: 312-8.

41. Kloner RA, Shook T, Przyklenk K, Davis VG, Junio L, Matthews $\mathrm{RV}$, et al. Previous angina alters in-hospital outcome in TIMI 4. A clinical correlate to preconditioning? Circulation 1995; 91: 37-45.

42. Ottani F, Galvani M, Ferrini D, Sorbello F, Limonetti P, Pantoli $\mathrm{D}$, et al. Prodromal angina limits infarct size. A role for ischemic preconditioning. Circulation 1995; 91: 291-7.

43. Lee TM, Su SF, Chou TF, Lee YT, Tsai CH. Loss of preconditioning by attenuated activation of myocardial ATP-sensitive potassium channels in elderly patients undergoing coronary angioplasty. Circulation 2002; 105: 334-40.

44. Abete P, Ferrara N, Cacciatore F, Madrid A, Bianco S, Calabrese C, et al. Angina-induced protection against myocardial infarction in adult and elderly patients: a loss of preconditioning mechanism in the aging heart? J Am Coll Cardiol 1997; 30: 947-54.

45. Wu ZK, Pehkonen E, Laurikka J, Kaukinen L, Honkonen EL, Kaukinen S, et al. The protective effects of preconditioning decline in aged patients undergoing coronary artery bypass grafting. J Thorac Cardiovasc Surg 2001; 122: 972-8.

46. Jaberansari MT, Baxter GF, Muller CA, Latouf SE, Roth E, Opie $\mathrm{LH}$, et al. Angiotensin-converting enzyme inhibition enhances a subthreshold stimulus to elicit delayed preconditioning in pig myocardium. J Am Coll Cardiol 2001; 37: 1996-2001.

47. Ebrahim Z, Baxter GF, Yellon DM. Omapatrilat limits infarct size and lowers the threshold for induction of myocardial preconditioning through a bradykinin receptor-mediated mechanism. Cardiovasc Drugs Ther 2004; 18: 127-34. 
48. Loubani M, Fowler A, Standen NB, Galinanes M. The effect of gliclazide and glibenclamide on preconditioning of the human myocardium. Eur J Pharmacol 2005; 515: 142-9.

49. Nguyen LT, Rebecchi MJ, Moore LC, Glass PS, Brink PR, Liu L. Attenuation of isoflurane-induced preconditioning and reactive oxygen species production in the senescent rat heart. Anesth Analg 2008; 107: 776-82.

50. Sniecinski R, Liu H. Reduced efficacy of volatile anesthetic preconditioning with advanced age in isolated rat myocardium. Anesthesiology 2004; 100: 589-97.

51. Heinen A, Huhn R, Smeele KM, Zuurbier CJ, Schlack W, Preckel B, et al. Helium-induced preconditioning in young and old rat heart: impact of mitochondrial $\mathrm{Ca}(2+)$-sensitive potassium channel activation. Anesthesiology 2008; 109: 830-6.

52. Peart JN, Gross ER, Headrick JP, Gross GJ. Impaired p38 MAPK/ HSP27 signaling underlies aging-related failure in opioid-mediated cardioprotection. J Mol Cell Cardiol 2007; 42: 972-80.

53. Peart JN, Gross GJ. Cardioprotective effects of acute and chronic opioid treatment are mediated via different signaling pathways. Am J Physiol Heart Circ Physiol 2006; 291: H1746-53.

54. Boengler K, Buechert A, Heinen Y, Roeskes C, Hilfiker-Kleiner D, Heusch G, et al. Cardioprotection by ischemic postconditioning is lost in aged and STAT3-deficient mice. Circ Res 2008; 102: 131-5.

55. Smith RM, Suleman N, Lacerda L, Opie LH, Akira S, Chien KR, et al. Genetic depletion of cardiac myocyte STAT-3 abolishes classical preconditioning. Cardiovasc Res 2004; 63: 611-6.

56. Redman LM, Rood J, Anton SD, Champagne C, Smith SR, Ravussin
E. Calorie restriction and bone health in young, overweight individuals. Arch Intern Med 2008; 168: 1859-66.

57. Shinmura K, Tamaki K, Bolli R. Short-term caloric restriction improves ischemic tolerance independent of opening of ATPsensitive $\mathrm{K}+$ channels in both young and aged hearts. J Mol Cell Cardiol 2005; 39: 285-96.

58. Tao L, Gao E, Jiao X, Yuan Y, Li S, Christopher TA, et al. Adiponectin cardioprotection after myocardial ischemia/reperfusion involves the reduction of oxidative/nitrative stress. Circulation 2007; 115: 1408-16.

59. Shinmura K, Tamaki K, Saito K, Nakano Y, Tobe T, Bolli R. Cardioprotective effects of short-term caloric restriction are mediated by adiponectin via activation of AMP-activated protein kinase. Circulation 2007; 116: 2809-17.

60. Abete P, Testa G, Galizia G, Mazzella F, Della Morte D, de Santis $\mathrm{D}$, et al. Tandem action of exercise training and food restriction completely preserves ischemic preconditioning in the aging heart. Exp Gerontol 2005; 40: 43-50.

61. Powers SK, Quindry J, Hamilton K. Aging, exercise, and cardioprotection. Ann N Y Acad Sci 2004; 1019: 462-70.

62. Abete P, Ferrara N, Cacciatore F, Sagnelli E, Manzi M, Carnovale V, et al. High level of physical activity preserves the cardioprotective effect of preinfarction angina in elderly patients. J Am Coll Cardiol 2001; 38: 1357-65.

63. Beltrami AP, Barlucchi L, Torella D, Baker M, Limana F, Chimenti $\mathrm{S}$, et al. Adult cardiac stem cells are multipotent and support myocardial regeneration. Cell 2003; 114: 763-76. 